Kalpa Publications in Engineering
Volume 2, 2018, Pages 59-66
Proceedings on International Conference on Emerg-
ing Trends in Expert Applications \& Security (2018)

\title{
A Detailed Analysis on Several Load Balancing Algorithm in Cloud Computing
}

\author{
Dr. Shubhra Saxena ${ }^{1}$, Dr. Navneet Sharma ${ }^{2}$, Dr. Akash Saxena ${ }^{3}$ and Dr. \\ Jayanti Goyal ${ }^{4}$ \\ 1,2,3,4 Associate Professor \\ ${ }^{1}$ SKIT, ${ }^{2}$ IIS University, ${ }^{3}$ Compucom Institute of Information technology and Management and \\ ${ }^{4}$ Kanoria PG Mahila Mahavidyalaya \\ Jaipur, India \\ ${ }^{1}$ shubhrasaxena123@gmail.com, ${ }^{2}$ navneetsharma1977@gmail.com, \\ ${ }^{3}$ akash27saxena@gmail.com, ${ }^{4}$ goyal.jayanti@gmail.com
}

\begin{abstract}
Cloud computing (CC) is rising rapidly; an expansive number of clients are pulled in towards cloud administrations for more fulfillments. Distributed computing is most recent developing innovation for expansive scale dispersed processing and parallel registering. CC gives vast pool of shared assets, program bundle, data, stockpile and a broad variety of uses according to client requests at any example of time. Adjusting the heap has turned out to be all the more intriguing examination zone in this field. Better load adjusting calculation in cloud framework builds the execution and assets use by progressively dispersing work stack among different hubs in the framework. Virtual machine (VM) is an execution unit that goes about as an establishment for distributed computing innovation. Bumble bee conduct propelled stack adjusting enhances the general throughput of handling and need construct adjusting centers with respect to decreasing the measure of time an errand needs to look out for a line of the VM.
\end{abstract}

\section{Introduction}

$\mathrm{CC}$ is changing all inclusive as it offer speedy and capable on-request benefits for storage room, system, programming, and equipment in the course of the Internet. CC offer newest accommodations to big business, organization, and the normal, metro and give ease figuring foundation to IT-based arrangement.

CC isn't latest association, for example, scholarly establishments, look into research facilities, and the military in urbanized nations has since quite a while ago utilized systems for correspondence, yet 
the setting cloud is most latest. It's currently used by an massive measure of clients to hide away touchy information on outsider servers, either for charge decrease or for ease of distribution.

These cloud layers are in conveyed models (private, open, group, and cross breed) in top of the line Mobility distributed computing (MCC). Client wavers to pass on worried in the cloud as unequivocal escape clause in its engineering create $\mathrm{CC}$ unstable. On-request relevance available in the cloud contains alteration; cyberassault has likewise augmented to dispatch unapproachable and dynamic assaults. A wide variety of systems or security calculations endeavor to help the mystery and safety measures of the cloud. This comprises of encrypting data, information save and correct retrieval and recovery to generate information recovery straightforward [1].

\section{Load Balancing}

LB into clouds is a method to allocate the load active local work-pressure lightly diagonally the entire node. It is use proposed for achieving an enhanced examination provisioning among source utilization relation, so improving the general performance of the system. Incoming household tasks are future from dissimilar location be received via the load balancer with then distributed toward the data center, for the proper weight distribution.

The intend of LB be as follow:

- To improve the availability of service with reserve utilization.

- To decrease the implementation time with waiting time of task coming as of dissimilar location.

- To develop the presentation with maintain system constancy.

- Build mistake acceptance system with accommodate future variation.

\section{Challenge of Load Balancing}

\subsection{Overhead Associated}

Decide the amount of overhead intricate as execute a heap adjusting framework. It is head of overhead appropriate for relationship of household tasks, between process correspondences. Straightforwardness must be thought with the goal that a heap adjusting calculation functions admirably.

\subsection{Throughput}

It is the measure of occupation performed inside the preset space of time. To advance the execution of the framework, throughput needs to be raised.

\subsection{Performance}

It can be expressed as the adequacy of the framework. It must be better Resource Utilization - is utilized test the usage of assets. It must be most noteworthy for a capable load adjusting framework. 


\subsection{Scalability}

The normal for benefit must be proportionate yet the measure of client increment. The supplementary amount of hubs compartment be supplementary select of aggravating the administration.

\subsection{Response Time}

Be ready to be expressed as the amount of time taken to react by a heap adjusting calculation inside a dispersed framework. For improved execution, this parameter must be consolidated.

\subsection{Fault Tolerance}

Despite the hub disappointment, the ability of a framework to complete predictable load adjusting. The heap adjusting is the for the most part extraordinary blame tolerant method [2].

\section{Load Balancing into Cloud Computing Environment}

Load balancing here $\mathrm{CC}$ present a skilled resolution in the direction of a range of issue residing within CC environment set of connections and convention. Load balancing should obtain interest in relation of two most important jobs, individual is the resource provisioning or else resource allocation with next is task expansion within distributed environment. Proficient scrutiny of property with expansion of property as fine as tasks will make certain.

1. Resources are simply accessible on command.

2. They are competently used below situation of increase/decrease load.

3. Power be save in situation of decreased load (i.e. when handling of cloud assets is less than definite limit).

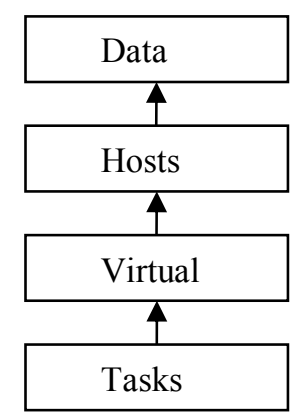

Figure 1: Class diagram of cloud [3] 


\section{Classification of Load Balancing Algorithm}

Load adjusting calculation can be for the most part sorted into two kinds:

\subsection{Static Algorithm}

\subsection{Dynamic Algorithm}

In Static Scheduling the dedication of household chores beside processors is expert past to program execution start i.e. in arrange time. Planning judgment depends on data on task execution time, passing out assets, and so forth, which is inconclusive to be acknowledged at arrange time. Static planning strategies are no preemptive. The point of static planning strategy is close diminish the when all is said in done execution time. These calculations can't get used to stack change in run-time. The dynamic load adjusting calculation tin be concentrated or circulated relying upon best of whether the risk for the mission of worldwide dynamic booking ought to in reality live in a specific processor (incorporated) or the work worried in settling on choices need to be physically conveyed among processors. However, focal calculation endures starting the issue of the blockage with single point failures. Dispersed load adjusting calculations are liberated from these challenges. once more conveyed dynamic planning can be agreeable or non-helpful. The heap adjusting trouble compartment is isolated keen on two sub issue: host.

1. Accommodation of new assignment use for VM provisioning with position of VMs lying on

2. Reallocation/migration of VMs. unique load adjusting calculation is available inside the writing which is discussed beneath.

\section{Evaluation Table of LB Method}

\begin{tabular}{|c|c|c|c|}
\hline $\begin{array}{ll}\text { Load } & \text { Balancing } \\
\text { Methods } & \end{array}$ & Parameter & Merit & Demerit \\
\hline $\begin{array}{l}\text { Quick Adaptive Load } \\
\text { Balancing Method [4] }\end{array}$ & $\begin{array}{l}\text { Efficiency } \\
\text { Communicatio } \\
\text { n Cost }\end{array}$ & $\begin{array}{l}\text { It gives Faster Balancing } \\
\text { Speed High Efficiency Low } \\
\text { Communication Overhead }\end{array}$ & $\begin{array}{l}\text { not uphold the } \\
\text { gy of cell }\end{array}$ \\
\hline $\begin{array}{l}\text { Honey } \text { Bee } \begin{aligned} & \text { Inspired } \\
& \text { Load } \text { Balancing } \\
& \text { Method [5] }\end{aligned}\end{array}$ & $\begin{array}{l}\text { Make traverse } \\
\text { Task Migration } \\
\text { Execution } \\
\text { Time }\end{array}$ & $\begin{array}{l}\text { Maximized } \\
\text { Waiting Throughput } \\
\text { Minimum Low Overhead }\end{array}$ & $\begin{array}{lr}\text { Less precedence } \\
\text { Load } \\
\text { ceaselessly on the } \\
\text { Queue }\end{array}$ \\
\hline $\begin{array}{lr}\text { Dynamic } & \text { and } \\
\text { Adaptive } \quad \text { Load } \\
\text { Balancing for Parallel } \\
\text { File System [6] } \\
\end{array}$ & $\begin{array}{l}\text { ghput } \\
\text { nse Time }\end{array}$ & $\begin{array}{l}\text { It provides more Scalability } \\
\text { duce the Decision holdup \& } \\
\text { improved } \\
\text { Utilization }\end{array}$ & $\begin{array}{l}\text { Deprivation of the } \\
\text { entire } \quad \text { System } \\
\text { because of Migration } \\
\text { Effect }\end{array}$ \\
\hline $\begin{array}{l}\text { Heat Diffusion Based } \\
\text { Dynamic } \quad \text { Load } \\
\text { Balancing Method [7] }\end{array}$ & $\begin{array}{lr}\text { Number of } \\
\text { Migrated Users } \\
\text { Number of } \\
\text { Overload } \\
\text { Servers }\end{array}$ & $\begin{array}{l}\text { Need extremely small } \\
\text { quantity of computation High } \\
\text { velocity }\end{array}$ & $\begin{array}{l}\text { Consumption of } \\
\text { instance Network } \\
\text { difficulty is more }\end{array}$ \\
\hline
\end{tabular}

Table 1: Load Balancing Methods 


\section{Literature Survey}

Ran et al. [8] in this paper, modifying backhaul stack in different cloud radio get the chance to organize. This paper proposes to modify the information to be transmit on backhauls of the RRHs to decrease the data trade breaking point of backhaul used by the RRHs or accomplish improved implementation with certain backhaul bind strikingly instead of weight frameworks.

Assi et al. [9] In this paper, the idea for adaptable movement organization over the cloud server ranches. This novel improvement brings new inconveniences, all around in the customs that manage its covered difficulties. The Traffic arranging in cloud server ranches is the critical difficulties that cover pull in thought from the investigation gathering, especially since the legacy traditions utilized as a part of server ranches offer constrained and un-versatile action organization. Various maintained for the utilization of VLANs as an approach to manage give flexible development organization; regardless, finding the ideal action crack along with the VLANs is the surprising NP-Complete VLAN task issue. The level of the pursuing area of the VLAN assignment issue is enormous, in spite of for negligible size structures.

Doyle et al. [10] in this paper, LB the Cloud for Carbon emission Control (Stratus structure) is broke down. The paper separates the power cost, carbon discharges, and commonplace organization request time for a gathering of conditions. The choice pertaining to how to change the assorted sections will rely upon SLAs, administration order, and the rate of carbon on exchange plans. Utilizing this data and the details of the cloud the administrator can dash the cloud in the most engaging mold. The strategy for the organization will comprehend whether a cloud provider can execute this estimation while appropriate in with advantage level understanding.

D. Zhang et al. [11] this paper, proposes a parallel tree structure that is used to section the reenactment district into sub-regions. The traits of this speedy adaptable changing system are to be adjusted the workload between the processors from neighborhoods overall regions. According to the refinement of workload, the game-plans of the cells are gotten. In any case, the essential workload centers around particular cells with the objective that the strategy for altering the vertices of the framework can be long an immediate aftereffect of the adjacent workload can be considered. This issue can be kept up a vital separation from by the speedy load changing flexible methodology. Here the locale should be distributed using the matched tree mode, with the objective that it contains leaf centers, youth center points, parent center points et cetera.

Vascak et al. [12] in this paper, Agent-Based CC Systems for Traffic Control is delineated. The need for a secure and financially beneficial action addresses a test for affecting development to profit frameworks. This work makes sense of how to join three essential considerations, particularly, cloudbased movements, head based frameworks and cushy based subjective maps to deal with the requirement. The proposing structure was immediate endeavored on a play zone, and got comes about were investigated using several picked the computation. At last, some further conceivable aftereffects of potential use and future research are shown.

\section{Research Methodology}

Honey bee conduct calculation is use inside this paper which be construct resting with respect to a state of bumble bee have the capacity to broaden itself over long separation as to get heaps of sustenance asset, for example, bloom fix by then these honey bee collect nectar or else dust beginning 
these source. A little segment of the province finds the earth look utilized for new blossom fix. What time of nourishment source be experience the investigate honey bees leave in the ground quick the hive with check use for include valuable. As they return next to the hive, the scouts unite the sustenance reaped. There be genuine a territory inside the hive said as the "move floor", where joggle move be perform by the honey bees to make an extremely valuable nourishment. Through the squirm move an investigate honey bee passes the circumstance of its hunt to at present watcher, which help in the utilization of the bloom fix. Here the time of the move be as indicated by the scout's positioning of the sustenance source, toward collect the most brilliant evaluated blossom fix different foragers discover enroll. At the point when move is finished, the scout comes again to the sustenance source it starts to see new nourishment. Until the nourishment is valuable, sustenance source resolve is post by means of the scouts when they revisit to their hive. Foragers who are enroll newly may squirm move also, which will be advance up the enlistment genius exceptionally gainful blossom fix. This autocatalytic method will go ahead to find essentially gainful blossom fix.

\section{Experimental Result}

Towards the begin, the underlying n scout honey bees are put aimlessly in VM on Cloud processing and $\mathrm{n}$ is that the scope of scout honey bees.

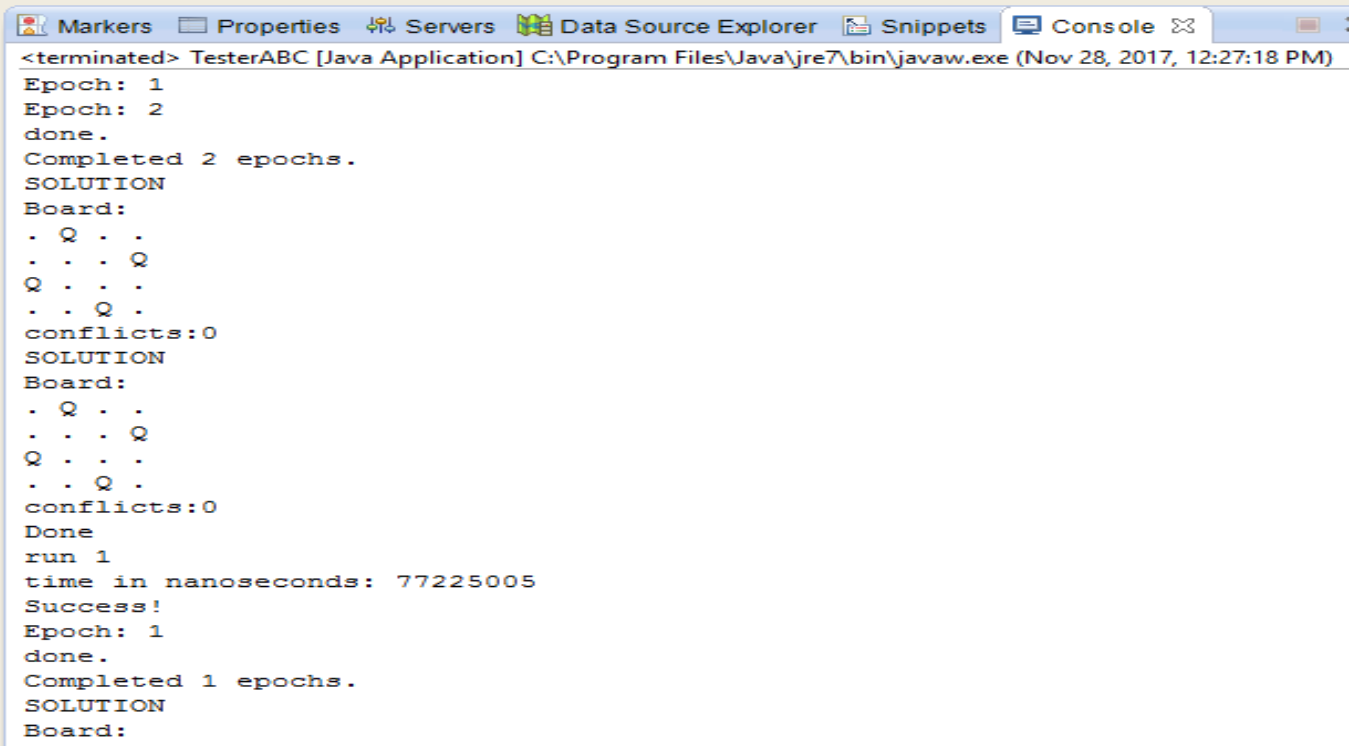

Figure 2: Screenshot of Run 1 


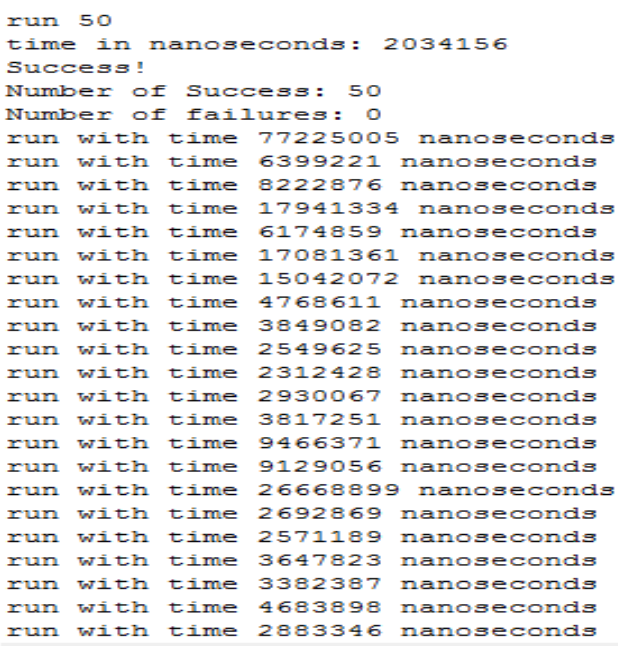

Figure 3: Screenshot of Run 50

\section{Calculating consume Running total time}

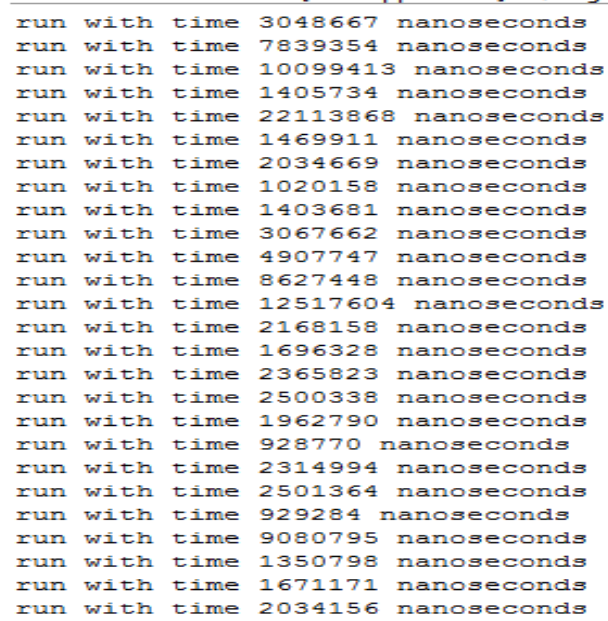

Figure 4: Total Running Time

In this section, there is a screenshots for showing the running of the result. We performed the execution of iterations till 50 runs and show the running time for the proper timing at each and final round.

\section{Conclusion}

$\mathrm{CC}$ offers most recent offices to endeavors, organizations, and the general, open and gives minimal effort registering foundation to IT-based arrangements. Load adjusting is a key part of distributed computing and evades the circumstance in which a few hubs end up over-burden while the 
others are sit or have little work to do. The dynamic load adjusting calculations can be unified or registering relying upon whether the obligation regarding the assignment of worldwide dynamic booking ought to physically dwell in a solitary processor (incorporated) or the work associated with settling on choices ought to be physically circulated among processors.

\section{References}

[1] Muhammad Yasir Shabir, Asif Iqbal, Zahid Mahmood, AtaUllah Ghafoor, "Analysis of Classical Encryption Techniques in CC", ISSN:111007-02141109/1011, pp102-113 Volume 21, Number 1, February 2016.

[2] Dharmesh Kashyap, Jaydeep Viradiya "A Survey Of Various Load Balancing Algorithms In Cloud Computing" International journal of scientific \& technology research volume 3, ISSUE 11, NOVEMBER 2014 ISSN 2277-8616.

[3] Kundan Pagar, Sachin Patil "A Survey on Load Balancing Techniques in Cloud Computing” International Journal of Science and Research (IJSR), Volume 3 Issue 12, December 2014.

[4] Dhinesh Babu L.D, P. VenkataKrishna, "Honey bee behavior inspired load balancing of tasks in cloud computing environments", Applied Soft Computing 13 (2013) 2292-2303.

[5] Bin Dong, Xiuqiao Li, Qimeng Wu, Limin Xiao, Li Ruan, “A dynamic and adaptive load balancing strategy for parallel file system with large-scale I/O servers", J. Parallel Distribution Computing. 72 (2012) 12541268.

[6] Yunhua Deng, Rynson W.H. Lau, "Heat diffusion based dynamic load balancing for distributed virtual environments", in: Proceedings of the17th ACM Symposium on Virtual Reality Software and Technology, ACM, 2010, pp. 203-210.

[7] Markus Esch, Eric Tobias, "Decentralized scale-free network construction and load balancing in Massive Multiuser Virtual Environments", in: Collaborative Computing: Networking, Applications and Worksharing, Collaborate Com, 2010, 6th International Conference on, IEEE, 2010, pp. 1-10.

[8] Ran, SK Jeya, J. Angela Jennifa Sujana, and T. Revathi. "Agent based bidirectional bidding mechanism for efficient scheduling of real time tasks in cloud computing." Electrical, Electronics, and Optimization Techniques (ICEEOT), International Conference on. IEEE, 2016.

[9] Assi, Cihan, et al., "Value of Service Based Task Scheduling for Cloud Computing Systems" ,ICCAC, 2016. 